\title{
Changes in family medicine visits across sociodemographic groups after the onset of the COVID-19 pandemic in Ontario: a retrospective cohort study
}

\author{
Ellen Stephenson PhD, Braden O’Neill MD DPhil, Jessica Gronsbell PhD, Debra A. Butt MD MSc, \\ Noah Crampton MD MSc, Catherine Ji MD MSc, Sumeet Kalia MSc, Christopher Meaney MSc, \\ Karen Tu MD MSc
}

\section{Abstract}

Background: It has been suggested that the COVID-19 pandemic has worsened socioeconomic disparities in access to primary care. Given these concerns, we investigated whether the pandemic affected visits to family physicians differently across sociodemographic groups.

Methods: We conducted a retrospective cohort study using electronic medical records from family physician practices within the University of Toronto Practice-Based Research Network. We evaluated primary care visits for a fixed cohort of patients who were active within the database as of Jan. 1, 2019, to estimate the number of patients who visited their family physician (visitor rate) and the number of distinct visits (visit volume) between Jan. 1, 2019, to June 30, 2020. We compared trends in visitor rate and visit volume during the pandemic (Mar. 14 to June 30, 2020) with the same period in the previous year (Mar. 14 to June 30, 2019) across sociodemographic factors, including age, sex, neighbourhood income, material deprivation and ethnic concentration.

Results: We included 365 family physicians and 372272 patients. Compared with the previous year, visitor rates during the pandemic period dropped by 34.5\%, from 357 visitors per 1000 people to 292 visitors per 1000 people. Declines in visit volume during the pandemic were less pronounced (21.8\% fewer visits), as the mean number of visits per patient increased during the pandemic (from 1.64 to 1.96). The declines in visitor rate and visit volume varied based on patient age and sex, but not socioeconomic status.

Interpretation: Although the number of visits to family physicians dropped substantially during the first few weeks of the COVID-19 pandemic in Ontario, patients from communities with low socioeconomic status did not appear to be disproportionately affected. In this primary care setting, the pandemic appears not to have worsened socioeconomic disparities in access to care.

T he COVID-19 pandemic has had profound effects on health care and society around the world. A major concern has been that health inequities attributed to socioeconomic disparities may be exacerbated, both in terms of the risk of developing COVID- $19,{ }^{1}$ as well as poor outcomes among those who become infected..$^{2-4}$ Supporting health equity has been an important feature of health system and primary care responses to COVID-19..$^{5-8}$

Although physical distancing and closure of nonessential businesses are considered important public health interventions to limit the spread of COVID-19, ${ }^{9}$ there are concerns that these public health measures may also lead to worsening social disparities ${ }^{10}$ and differential access to health care services, which could lead to poorer health outcomes both during the pandemic and in the future. The existence of socioeconomic disparities in primary care is well established across jurisdictions; ${ }^{11,12}$ however, the extent to which the COVID-19 pandemic is worsening these disparities is not well understood.
The objective of this study was to assess the impact of the COVID-19 pandemic on access to family physician services across sociodemographic groups. We hypothesized that the effects of COVID-19 would be greatest in patients of lower socioeconomic status.

Competing interests: Jessica Gronsbell reports acting as a scientific advisor for Verily Life Sciences. No other competing interests were declared.

Disclaimer: Braden O'Neill is an associate editor of CMAJ and CMAJ Open. He was not involved in the editorial decision-making process for this article.

This article has been peer reviewed.

Correspondence to: Ellen Stephenson, ellen.stephenson@utoronto.ca CMAJ Open 2021. DOI:10.9778/cmajo.20210005 


\section{Methods}

\section{Study design}

We used a retrospective cohort design in which we evaluated primary care visits for a fixed cohort of patients over an 18-month period (Jan. 1, 2019, to June 30, 2020) that included the onset of the COVID-19 pandemic in March 2020. We used a fixed cohort of patients to minimize the impact of potential changes in access to care for new patients.

\section{Setting}

In Ontario, Canada, substantial changes occurred to the health care system with the onset of the pandemic. Ontario has a government, single-payer health system through the Ontario Health Insurance Plan, which covers primary and hospital care for most Ontario residents. ${ }^{13}$ At the start of the COVID-19 pandemic in mid-March 2020, nonessential hospital services were ordered to be substantially reduced, ${ }^{14}$ and family physicians were advised to switch to virtual (phone or video) visits as much as possible, instead of meeting patients in person. ${ }^{15}$ This change was incentivized through the introduction of billing codes for virtual visits that were equivalent to those used for in-person visits. ${ }^{16}$ Before this change, virtual visits in primary care were not widely used as insured services in Ontario. ${ }^{17,18}$ This unprecedented modification to family medicine in Ontario occurred concurrently with public health interventions, including a provincial state of emergency that instructed the population to leave home for only essential purposes, such as accessing health care. ${ }^{19}$

\section{Data source}

We used data from the University of Toronto Practice-Based Research Network (UTOPIAN) Data Safe Haven, a database of primary care electronic medical records (EMRs). ${ }^{20}$ This database includes records from 89 family medicine clinics in Ontario, including 365 physicians, $77 \%$ of whom practise in the Greater Toronto Area. All records of interactions between UTOPIAN family physicians and their patients that are documented in the EMR are part of the UTOPIAN database. It does not capture services provided by other health care providers or specialists. In general, EMR data from primary care have been found to be reasonably comprehensive and complete. ${ }^{21,22}$

\section{Participants}

We included family physicians who had billing, medication and laboratory data recorded for at least $20 \%$ of their patients, had at least 200 rostered patients, and started using their EMR on or before Jan. 1, 2019. To identify valid records for family practice patients, patients were required to have their sex and month and year of birth recorded, and to have been rostered to a participating physician or have had at least 1 periodic health exam or at least 2 visits with a participating physician within the past 3 years. We included patients whose first entry in the EMR was recorded on or before Jan. 1, 2019. Patients who were born after Jan. 1, 2019, were eligible for inclusion if they had at least 1 visit documented in the EMR (Appendix 1, available at www.cmajopen.ca/content/9/2/ E651/suppl/DC1).

\section{Outcomes}

We used 2 outcome measures: the number of unique patients seen during a fixed period of time (visitor rate), and the number of distinct family physician visits that occurred during a fixed period of time (visit volume). We calculated both outcomes as a rate per 1000 patients in the research cohort. We defined a family physician visit based on service billing codes recorded within the EMR. A detailed description of the codes interpreted as a family physician office visit is provided in Appendix 1. We counted a maximum of 1 in-person visit and 1 virtual visit via telephone or video per patient per day.

\section{Sociodemographic measures}

We extracted age and sex from the patient's EMR. We derived neighbourhood income, material deprivation and ethnic concentration from the patient's postal code, mapped to previously defined quintiles for neighbourhood income, ${ }^{23}$ and the material deprivation and ethnic concentration dimensions of the Ontario Marginalization Index. ${ }^{24,25}$ Material deprivation refers to the inability for individuals and communities to access and attain basic material needs, which is a useful proxy for an individual's socioeconomic status. ${ }^{24}$ Ethnic concentration refers to the area-level concentration of people who are recent immigrants or members of a visible minority group, defined by Statistics Canada as "persons, other than Aboriginal peoples, who are non-Caucasian in race or non-white in colour."24 The Ontario Marginalization Index is a validated measure that has been used to study health inequalities, including the epidemiology of COVID-19. ${ }^{26}$

\section{Statistical analysis}

To evaluate whether sociodemographic factors were associated with access to family physician services, we conducted 3 main analyses. First, we characterized global differences in access to family physician services across the entire observation window. We used $\chi^{2}$ tests to evaluate sociodemographic differences between patients in the cohort who visited their family physician at least once during the 18 -month study period (visitors) to those who did not have any visits (nonvisitors). Next, we calculated weekly visit volume from Jan. 1, 2019, to June 30, 2020, to assess trends across the various sociodemographic groups before and during the pandemic period. We then focused our analysis on the pandemic period (Mar. 14 to June 30, 2020) and compared visit volume in this period to the same period in the previous year (Mar. 14 to June 30, 2019) to account for potential seasonality effects in family physician visits. We computed $95 \%$ confidence intervals for the difference in visit volume across these periods, stratified by sociodemographic factors, to evaluate the impact of COVID-19 on care across different populations. We also performed the same analysis for visitor rate to assess differences in the number of unique patients seen in the 2 periods. 


\section{Sensitivity analysis}

We conducted analogous analyses for the prepandemic period (Jan. 1, 2019, to Mar. 13, 2019, compared with Jan. 1, 2020, to Mar. 13, 2020) to determine if there were pre-existing differences in the year-over-year change in visitor rate or visit volume in the months preceding the onset of the pandemic in 2020.

\section{Ethics approval}

This study was approved through the University of Toronto (\#40129) and North York General Hospital (\#20-0044) research ethics boards.

\section{Resullts}

A total of 365 family physicians and 372272 patients met criteria for inclusion in the research cohort (Figure 1). From Jan. 1, 2019, to June 30, 2020, there were 1115691 distinct visits and 952 instances when a patient had both an in-person visit and a virtual visit within the same day. Across the 18-month observation period, $276144(74.2 \%)$ patients had at least 1 family physician visit; 96128 (25.8\%) patients did not have any visits with their UTOPIAN family physician. Patients who did not see their family physician during the study period were younger, more likely to be male and more likely to be from neighbourhoods with the lowest income, most material deprivation and most ethnic diversity (Table 1). After the onset of the COVID-19 pandemic, 159415 (85.1\%) patient visits during the study period (Mar. 14 to June 30, 2020) occurred virtually via telephone or video.

\section{Change in visit volume after pandemic onset}

Weekly visit volume before and after the onset of the pandemic, by patient sex and age, neighbourhood income, material deprivation and ethnic concentration, is summarized in Figure 2. In the prepandemic period, visit volume was nearly identical to the year before, but with the onset of the

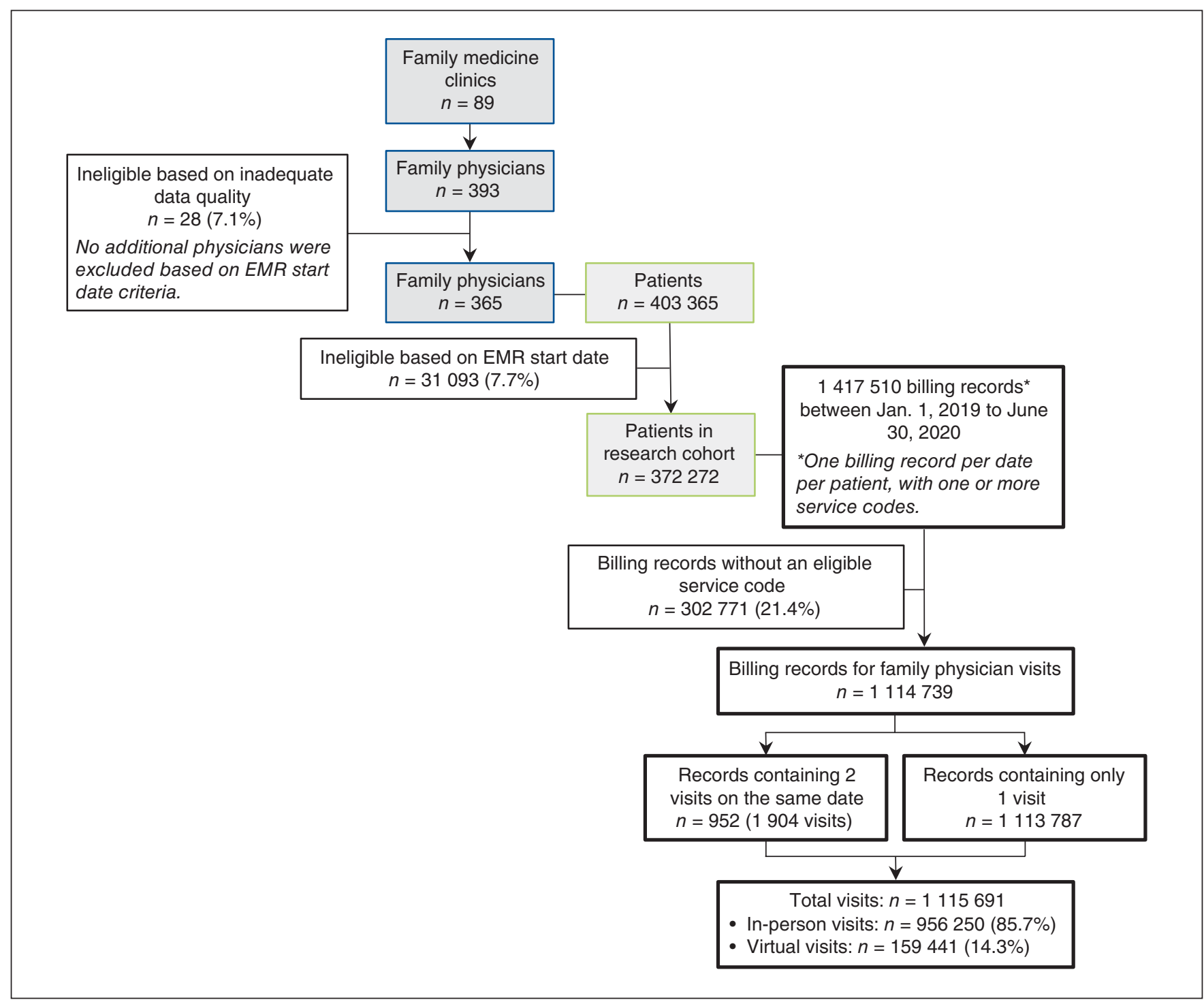

Figure 1: Cohort selection process. Note: EMR = electronic medical record. 
Research

\begin{tabular}{|c|c|c|c|c|}
\hline \multirow[b]{2}{*}{ Characteristic } & \multicolumn{3}{|c|}{ No. $(\%)$ of patients* } & \multirow[b]{2}{*}{$p$ value } \\
\hline & $\begin{array}{c}\text { All patients } \\
n=372272\end{array}$ & $\begin{array}{c}\text { Patients with } 1 \text { or more } \\
\text { visits } \\
n=276144\end{array}$ & $\begin{array}{c}\text { Patients without any } \\
\text { visits } \\
n=96128\end{array}$ & \\
\hline Age, yr, mean \pm SD & $43.07 \pm 23.18$ & $44.95 \pm 23.38$ & $37.66 \pm 21.71$ & $p<0.001$ \\
\hline Age groups, yr & & & & $p<0.001$ \\
\hline$\leq 18$ & $67481(18.1)$ & $46150(16.7)$ & 21331 (22.2) & \\
\hline $19-34$ & 71168 (19.1) & $46386(16.8)$ & $24782(25.8)$ & \\
\hline $34-49$ & $78217(21.0)$ & 55997 (20.3) & $22220(23.1)$ & \\
\hline $50-64$ & $80885(21.7)$ & 64434 (23.3) & $16451(17.1)$ & \\
\hline$\geq 65$ & $74521(20.0)$ & 63177 (22.9) & $11344(11.8)$ & \\
\hline Sex & & & & $p<0.001$ \\
\hline Female & 205877 (55.3) & $160171(58.0)$ & $45706(47.6)$ & \\
\hline Male & $166395(44.7)$ & $115973(42.0)$ & $50422(52.5)$ & \\
\hline Income quintiles & & & & $p<0.001$ \\
\hline 1 (lowest income) & $68948(18.5)$ & $49622(18.0)$ & $19326(20.1)$ & \\
\hline 2 & $58900(15.8)$ & $43892(15.9)$ & $15008(15.6)$ & \\
\hline 3 & $61686(16.6)$ & $46214(16.7)$ & $15472(16.1)$ & \\
\hline 4 & 72723 (19.5) & $54506(19.7)$ & $18217(19.0)$ & \\
\hline 5 (highest income) & $100665(27.0)$ & $76048(27.5)$ & $24617(25.6)$ & \\
\hline Missing & $9350(2.5)$ & $5862(2.1)$ & $3488(3.6)$ & \\
\hline Material deprivation quintiles & & & & $p<0.001$ \\
\hline 1 (least deprived) & $95042(25.5)$ & $72057(26.1)$ & 22985 (23.9) & \\
\hline 2 & $86220(23.2)$ & $64671(23.4)$ & $21549(22.4)$ & \\
\hline 3 & $68833(18.5)$ & $51536(18.6)$ & $17297(18.0)$ & \\
\hline 4 & $56648(15.2)$ & $42270(15.3)$ & $14378(15.0)$ & \\
\hline 5 (most deprived) & $55117(14.8)$ & 39054 (14.2) & $16063(16.7)$ & \\
\hline Missing & $10412(2.8)$ & $6556(2.4)$ & $3856(4.0)$ & \\
\hline Ethnic concentration quintiles & & & & $p<0.001$ \\
\hline 1 (least diverse) & $35638(9.6)$ & $26918(9.8)$ & $8720(9.1)$ & \\
\hline 2 & $48074(12.9)$ & $35979(13.0)$ & 12095 (12.6) & \\
\hline 3 & $68546(18.4)$ & $51473(18.6)$ & $17073(17.8)$ & \\
\hline 4 & 96757 (26.0) & $72948(26.4)$ & 23809 (24.8) & \\
\hline 5 (most diverse) & $112845(30.3)$ & $82270(29.8)$ & 30575 (31.8) & \\
\hline Missing & $10412(2.8)$ & $6556(2.4)$ & $3856(4.0)$ & \\
\hline
\end{tabular}

COVID-19 pandemic, visit volume declined substantially (Table 2). From Mar. 14 to June 30, 2020, the overall visit volume dropped to 503 visits per 1000 patients from 644 visits per 1000 patients the same time the year before $(21.8 \%$ fewer visits).

Changes in visit volume differed based on patient age and sex, with larger changes observed among male (-25.5\%) compared with female $(-19.5 \%)$ patients, and among patients aged 18 years and younger $(-36.3 \%)$ compared with patients aged $19-34(-14.7 \%)$ and $35-49$ years $(-17.3 \%)$.
Patients from different income, material deprivation and ethnic concentration quintiles showed only modest differences with respect to relative decreases in visit volume during the pandemic period (Table 2).

\section{Change in visitor rate after pandemic onset}

The overall visitor rate was 257 per 1000 patients from Mar. 14 to June 30, 2020, compared with 392 per 1000 patients for the same dates in 2019 , with $34.5 \%$ fewer unique patients visiting their family physician. As the percent change 


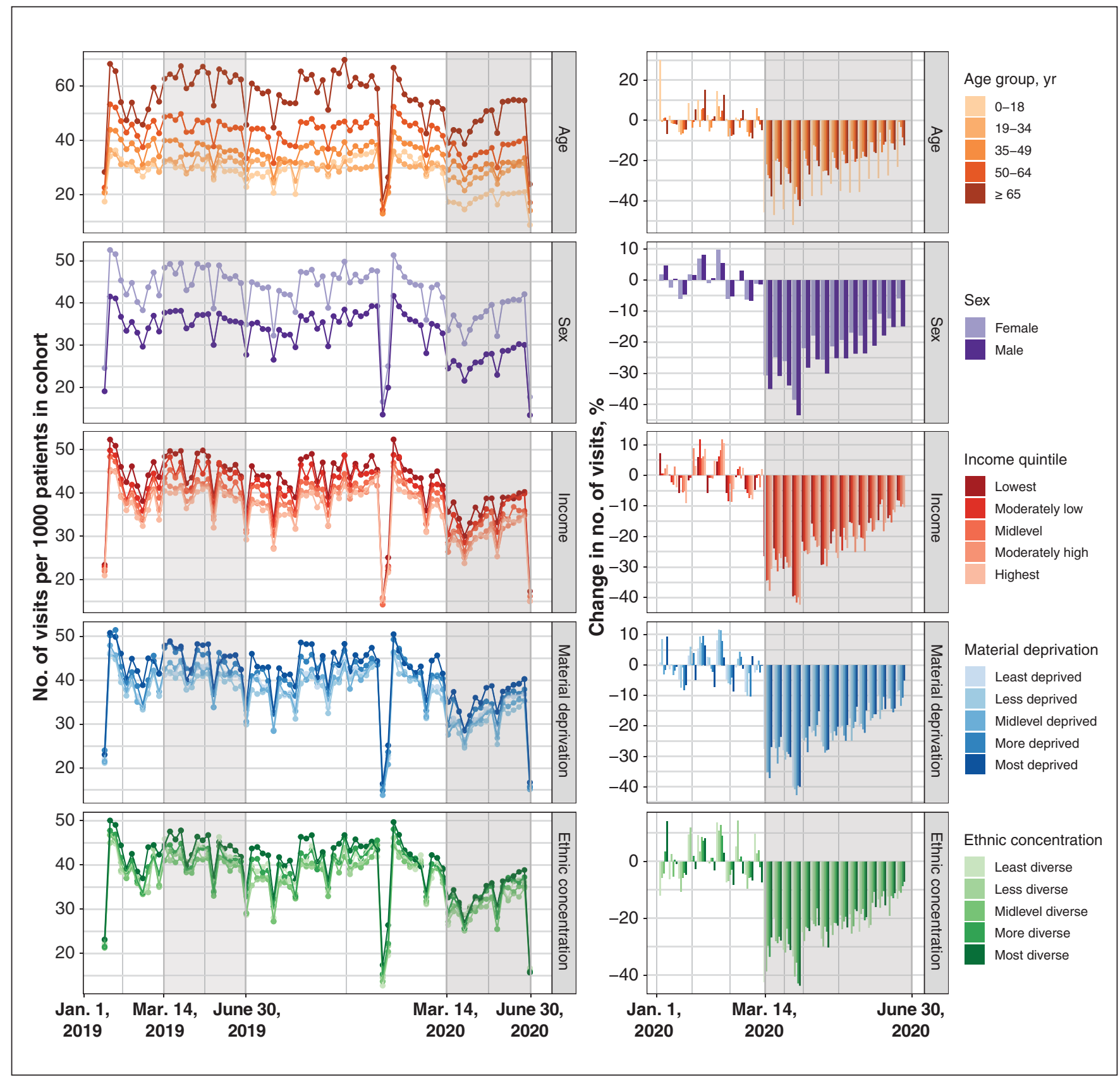

Figure 2: Change in weekly visit volume (total number of visits per 1000 patients in cohort), stratified by patient age, sex and neighbourhood characteristics (income, material deprivation and ethnic concentration). The shaded grey area indicates the 2020 pandemic period (Mar. 14 to June 30) and corresponding period in 2019. A reduction in visit volume is observed during the Christmas and New Year holiday period. Some clinics operate at reduced capacity or close during this period such that it is not unusual for visit volume to be substantially reduced.

in the number of patients accessing care (visitor rate) was larger than the percent change in total number of visits, the average number of visits per visitor increased during the pandemic period to 1.96 from 1.64 for the same time the year before. Changes in visitor rate associated with the pandemic varied based on patient age and sex, with larger relative decreases among male patients $(-37.0 \%)$ compared with female patients $(-32.9 \%)$, and among patients aged 18 years and younger $(-44.0 \%)$ compared with patients aged 19-34 $(-29.7 \%)$ and $35-49(-32.3 \%)$ years. Patients from different income, material deprivation and ethnic concentration quintiles showed similar relative decreases in visitor rates during the pandemic period (Table 2).

\section{Sensitivity analysis}

Analyses for the prepandemic period (Jan. 1 to Mar. 13, 2019, compared with Jan. 1 to Mar. 13, 2020) showed that there were no pre-existing differences in the year-over-year change in visitor rate or visit volume in the months preceding the onset of the pandemic (Appendix 1, Table S1). 
Research

\begin{tabular}{|c|c|c|c|c|c|c|c|c|}
\hline \multirow[b]{2}{*}{ Variable } & \multicolumn{4}{|c|}{ Visitor rate per 1000 patients } & \multicolumn{4}{|c|}{ Visit volume per 1000 patients } \\
\hline & 2019 rate & 2020 rate & Difference $(95 \% \mathrm{Cl})$ & $\begin{array}{c}\text { Change, } \\
\%\end{array}$ & $\begin{array}{c}2019 \\
\text { volume }\end{array}$ & $\begin{array}{c}2020 \\
\text { volume }\end{array}$ & Difference $(95 \% \mathrm{Cl})$ & $\begin{array}{c}\text { Change, } \\
\%\end{array}$ \\
\hline All patients & 392 & 257 & $-135(-137$ to -134$)$ & -34.5 & 644 & 503 & $-140(-145$ to -136$)$ & -21.8 \\
\hline \multicolumn{9}{|l|}{ By patient sex } \\
\hline Female & 425 & 285 & $-140(-142$ to -137$)$ & -32.9 & 715 & 576 & $-139(-146$ to -133$)$ & -19.5 \\
\hline Male & 352 & 222 & $-130(-133$ to -127$)$ & -37.0 & 555 & 414 & $-141(-147$ to -135$)$ & -25.5 \\
\hline \multicolumn{9}{|l|}{ By patient age, yr } \\
\hline$\leq 18$ & 301 & 169 & $-132(-137$ to -128$)$ & -44.0 & 459 & 292 & $-167(-175$ to -158$)$ & -36.3 \\
\hline $19-34$ & 305 & 214 & $-91(-95$ to -87$)$ & -29.7 & 495 & 422 & $-73(-83$ to -63$)$ & -14.7 \\
\hline $34-49$ & 352 & 239 & $-114(-118$ to -110$)$ & -32.3 & 568 & 470 & $-98(-108$ to -89$)$ & -17.3 \\
\hline $50-64$ & 434 & 288 & $-146(-150$ to -142$)$ & -33.6 & 703 & 560 & $-143(-152$ to -133$)$ & -20.3 \\
\hline$\geq 65$ & 554 & 362 & $-192(-196$ to -188$)$ & -34.6 & 968 & 746 & $-222(-234$ to -211$)$ & -23.0 \\
\hline \multicolumn{9}{|l|}{ By income quintile } \\
\hline 1 (lowest income) & 404 & 270 & $-134(-138$ to -130$)$ & -33.2 & 715 & 569 & $-146(-157$ to -135$)$ & -20.4 \\
\hline 2 & 405 & 268 & $-137(-142$ to -133$)$ & -33.9 & 682 & 538 & $-144(-156$ to -133$)$ & -21.2 \\
\hline 3 & 396 & 260 & $-136(-141$ to -132$)$ & -34.4 & 644 & 506 & $-138(-149$ to -127$)$ & -21.4 \\
\hline 4 & 385 & 249 & $-137(-141$ to -132$)$ & -35.4 & 617 & 471 & $-145(-155$ to -136$)$ & -23.6 \\
\hline 5 (highest income) & 387 & 250 & $-137(-140$ to -133$)$ & -35.3 & 601 & 468 & $-133(-141$ to -125$)$ & -22.1 \\
\hline Missing & 317 & 212 & $-106(-117$ to -95$)$ & -33.3 & 544 & 415 & $-128(-156$ to -101$)$ & -23.6 \\
\hline \multicolumn{9}{|l|}{$\begin{array}{l}\text { By material deprivation } \\
\text { quintile }\end{array}$} \\
\hline 1 (least deprived) & 395 & 258 & $-137(-141$ to -133$)$ & -34.6 & 631 & 504 & $-127(-135$ to -118$)$ & -20.1 \\
\hline 2 & 387 & 250 & $-137(-141$ to -133$)$ & -35.5 & 613 & 474 & $-139(-148$ to -130$)$ & -22.6 \\
\hline 3 & 394 & 257 & $-137(-141$ to -132$)$ & -34.7 & 637 & 489 & $-149(-159$ to -139$)$ & -23.4 \\
\hline 4 & 405 & 266 & $-139(-144$ to -134$)$ & -34.3 & 683 & 527 & $-156(-168$ to -145$)$ & -22.9 \\
\hline 5 (most deprived) & 395 & 265 & $-130(-135$ to -125$)$ & -32.9 & 697 & 560 & $-138(-150$ to -125$)$ & -19.7 \\
\hline Missing & 321 & 212 & $-108(-119$ to -98$)$ & -33.8 & 558 & 411 & $-147(-172$ to -121$)$ & -26.3 \\
\hline \multicolumn{9}{|c|}{ By ethnic concentration quintile } \\
\hline 1 (least diverse) & 401 & 269 & $-132(-138$ to -126$)$ & -32.9 & 649 & 503 & $-146(-158$ to -130$)$ & -22.5 \\
\hline 2 & 387 & 256 & $-131(-136$ to -126$)$ & -33.9 & 623 & 469 & $-154(-163$ to -140$)$ & -24.7 \\
\hline 3 & 386 & 255 & $-131(-135$ to -126$)$ & -33.9 & 614 & 487 & $-127(-135$ to -115$)$ & -20.7 \\
\hline 4 & 398 & 260 & $-139(-142$ to -135$)$ & -34.8 & 642 & 507 & $-135(-141$ to -123$)$ & -21.0 \\
\hline 5 (most diverse) & 397 & 257 & $-141(-144$ to -137$)$ & -35.4 & 678 & 525 & $-153(-159$ to -142$)$ & -22.6 \\
\hline Missing & 321 & 212 & $-108(-119$ to -98$)$ & -33.8 & 558 & 411 & $-147(-172$ to -121$)$ & -26.3 \\
\hline
\end{tabular}

\section{Interpretation}

Despite concerns of worsening socioeconomic disparities in health care related to the COVID-19 pandemic, ${ }^{10}$ we did not find that declines in the use of family physician services during the early pandemic period disproportionally affected patients from socially disadvantaged communities. The number of patients with at least 1 family physician visit declined substantially with the onset of the pandemic, but this decline was similar across socioeconomic groups. Changes in the total number of visits were also similar across socioeconomic groups, with slightly smaller, not larger, declines among patients from lowincome and materially deprived neighbourhoods.

A recent study of changes in primary care across Ontario related to COVID-19 also found that declines in visit volume were smaller among patients from lower income communities, ${ }^{27}$ but did not consider changes in the number of patients who were accessing care at least once over a longer period of time. Increases in the number of contacts per patient during the pandemic (e.g., multiple virtual visits or a 
telephone visit followed by an in-person visit, if deemed necessary) have the potential to mask underlying declines in the number of patients who are accessing care. Our findings suggest that the pandemic has led to an increase in the number of visits per visitor, but has not disproportionately affected the underlying number of visitors from different socioeconomic groups.

The increased availability of virtual care may have helped ease some barriers to accessing health care, such as the need to commute to appointments, take time off work or arrange child care. Before the pandemic, virtual care in Ontario was used most often by people living in low-income and rural communities, ${ }^{18}$ where the availability and accessibility of primary care services were more limited. Other research has also shown that, when given a choice between meeting face-toface or via telemedicine, patients with lower socioeconomic status are more likely to choose telemedicine. ${ }^{28}$ With the rapid expansion of virtual care services in response to COVID-19, it will be important to ensure that new barriers to receiving high-quality health care are not created. Randomized trials have shown that virtual care can be equally effective to usual care for some conditions, ${ }^{29-31}$ but some primary care services cannot be provided virtually. Further research is needed to evaluate how virtual care can be used to improve both access to care and the quality of care provided.

\section{Limitations}

Our analysis was limited to events that occurred in 2019 and the first half of 2020 for a convenience sample of family physicians in Ontario. Only visits with UTOPIAN providers were captured in this study. Patients may have accessed services from other providers and this is not captured. This study focused on a "pandemic period" that included the first 16 weeks of the COVID-19 pandemic. The effects of the pandemic are ongoing and trends may have changed over time. The patients and practices used by the physicians and clinics in the UTOPIAN network are not necessarily representative of the experience in other settings. Patients in the current study were insured through a government-funded insurance plan, such that disparities in loss of employment that occurred during the pandemic ${ }^{31}$ did not affect insurance coverage.

We also focused on patients who recently visited or were currently rostered to a family physician (a process in Ontario where a patient-physician relationship is formally established, and physicians are compensated through a blended capitation payment model). Past research has found that patients without a regular family physician are more likely to be male, younger or a recent immigrant. ${ }^{32}$ The extent to which these disparities in access to a regular family physician have worsened during the COVID-19 pandemic is an area for further research.

We used neighbourhood-level measures of income, material deprivation and ethnic concentration; patient-level measures may yield different results. Our findings should be interpreted with respect to area-level socioeconomic differences, recognizing that the experience within communities is not necessarily homogenous and that there may be disparities across people within neighbourhoods that could not be observed in the current study. We did not consider reasons for visiting a family physician in the current analysis, which may vary based on underlying health risks (e.g., disease comorbidities) and patient demographic characteristics (e.g., age, sex). Further investigation is needed to understand if health services provided during the pandemic are reaching those with the greatest needs.

\section{Conclusion}

Overall, our findings show that the rate and volume of visits to family physicians changed substantially during the first few months of the COVID-19 pandemic in Ontario, Canada. Fewer patients accessed services, with fewer office visits and more virtual care. The swift response to the COVID-19 pandemic in primary care appears to have been successful in maintaining access to care across socioeconomic groups in our study setting. Nevertheless, efforts to assess and minimize socioeconomic disparities in health care are still needed as the effects of the COVID-19 pandemic continue to evolve.

\section{References}

1. Hatef E, Chang HY, Kitchen C, et al. Assessing the impact of neighborhood socioeconomic characteristics on COVID-19 prevalence across seven states in the United States. Front Public Health 2020;8:571808.

2. Chaudhry R, Dranitsaris G, Mubashir T, et al. A country level analysis measuring the impact of government actions, country preparedness and socioeconomic factors on COVID-19 mortality and related health outcomes. EClinicalMedicine 2020;25:100464.

3. Azar KMJ, Shen Z, Romanelli RJ, et al. Disparities in outcomes among COVID-19 patients in a large health care system in California. Health Aff (Millwood) 2020;39:1253-62.

4. Raine S, Liu A, Mintz J, et al. Racial and ethnic disparities in covid-19 outcomes: Social determination of health. Int 7 Environ Res Public Health 2020;17:1-16.

5. Berkowitz SA, Cené CW, Chatterjee A. Covid-19 and health equity - time to think big. N Engl f Med 2020;383:e76.

6. O'Neill B, Ferrer R, O'Brien P, et al. Improving equity through primary care: proceedings of the 2019 Toronto International Conference on quality in primary care. Ann Fam Med 2020;18:364-9.

7. Wolfson JA, Leung CW. An opportunity to emphasize equity, social determinants, and prevention in primary care. Ann Fam Med 2020;18:290-1.

8. Williams DR, Cooper LA. COVID-19 and health equity - a new kind of "herd immunity." FAMA 2020;323:2478-80.

9. Lewnard JA, Lo NC. Scientific and ethical basis for social-distancing interventions against COVID-19. Lancet Infect Dis 2020;20:631-3.

10. Silva DS, Smith MJ. Social distancing, social justice, and risk during the COVID-19 pandemic. Can 7 Public Health 2020;1 11:459-61.

11. Olah ME, Gaisano G, Hwang SW. The effect of socioeconomic status on access to primary care: an audit study. CMA7 2013;185:E263-9.

12. Griffith K, Evans L, Bor J. The affordable care act reduced socioeconomic disparities in health care access. Health Aff (Millwood) 2017;36:1503-10.

13. What OHIP covers. Service Ontario; 2020. Available: https://www.ontario.ca/ page/what-ohip-covers (accessed 2020 Dec. 11).

14. Agnus H, Willams D, Anderson M. Ramping down elective surgeries and other non-emergent activities [memorandum]. Toronto: Office of the Deputy Minister, Ontario Ministry of Health; 2020 Mar. 15. Available: https://www. oha.com/Bulletins/DM\%20OH\%20CMOH\%20memo\%20COVID19\%20 elective\%20surgery\%20(2020-03-15).pdf (accessed 2020 Nov. 30).

15. Primary care changes in response to corona virus (COVID-19) effective March 14, 2020 [INFOBulletin]. Negotiations Branch, Ontario Ministry of Health; 2020. Available: http://www.health.gov.on.ca/en/pro/programs/ohip/ bulletins/11000/bul11229.aspx (accessed 2020 Nov. 30).

16. Changes to the Schedule of Benefits for Physician Services (schedule) in response to COVID-19 influenza pandemic effective March 14, 2020 [INFOBulletin]. Health Services Branch, Ontario Ministry of Health; 2020. Available: http://www.health.gov.on.ca/en/pro/programs/ohip/bulletins/4000/ bul4745.aspx (accessed 2020 Nov. 30).

17. Agarwal P, Kithulegoda N, Umpierre R, et al. Telemedicine in the driver's seat: new role for primary care access in Brazil and Canada. Can Fam Physician 2020;66:104-11.

18. Ontario enacts declaration of emergency to protect the public [news release]. Ontario Ministry of Health; 2020 Mar. 17. Available: https://news.ontario.ca/en/ 
release/56356/ontario-enacts-declaration-of-emergency-to-protect-the-public (accessed 2020 Nov. 30).

19. Benchimol EI, Smeeth L, Guttmann A, et al. The REporting of studies Conducted using Observational Routinely collected health Data (RECORD) Statement. PLoS Med 2015;12:e1001885.

20. Tu K, Sodhi S, Kidd M, et al. The University of Toronto family medicine report: caring for our diverse populations. Toronto: 2020.

21. Tu K, Mitiku TF, Ivers NM, et al. Evaluation of electronic medical record administrative data linked database (EMRALD). Am 7 Manag Care 2014; 20:e15-e21.

22. Tu K, Widdifield J, Young J, et al. Are family physicians comprehensively using electronic medical records such that the data can be used for secondary purposes? A Canadian perspective. BMC Med Inform Decis Mak 2015; 15:67.

23. Postal Code OM Conversion File Plus. $(P C C F+)$ version $7 C$, reference guide. Ottawa: Statistics Canada; 2019.

24. Matheson F, Moloney G, van Ingen T. 2016 Ontario Marginalization Index user guide. Toronto: St. Michaels' and Public Health Ontario; 2016

25. Matheson FI, Dunn JR, Smith KLW, et al. Development of the Canadian Marginalization Index: a new tool for the study of inequality. Can 7 Public Health 2012;103:(8 Suppl 2):S12-6.

26. COVID-19 in Ontario - a focus on diversity: January 15, 2020 to May 14, 2020 Toronto: Ontario Agency for Health Protection and Promotion (Public Health Ontario); 2020.

27. How COVID-19 affected physician services. Ottawa: Canadian Institute for Health Information; 2020. Available: https://www.cihi.ca/en/covid-19 -resources/impact-of-covid-19-on-canadas-health-care-systems/how-covid-19 -affected-physician-services (accessed 2020 Nov. 19).

28. Bhatia RS, Jamieson T, Shaw J, et al. Canada's virtual care revolution: a framework for success. Toronto: C.D. Howe Institute; 2020

29. Alexander GC, Tajanlangit M, Heyward J, et al. Use and content of primary care office-based vs telemedicine care visits during the COVID-19 pandemic in the US. FAMA Netw Open 2020;3:e2021476.

30. Sigurdsson EL, Blondal AB, Jonsson JS, et al. How primary healthcare in Iceland swiftly changed its strategy in response to the COVID-19 pandemic. BMF Open 2020;10:e 043151.

31. Agarwal SD, Sommers BD. Insurance coverage after job loss - the importance of the ACA during the COVID-associated recession. $N$ Engl 7 Med 2020;383:1603-6.

32. Hay C, Pacey M, Bains N, et al. Understanding the unattached population in Ontario: evidence from the Primary Care Access Survey (PCAS). Healthc Policy 2010;6:33-47.
Affiliations: Department of Family and Community Medicine (Stephenson, O’Neill, Butt, Crampton, Ji, Kalia, Meaney, Tu), University of Toronto; MAP Centre for Urban Health Solutions (O'Neill), St. Michael's Hospital; North York General Hospital (Tu); Department of Statistical Sciences (Gronsbell), University of Toronto; Scarborough Health Network (Butt); Toronto Western Hospital Family Health Team (Crampton, Ji, Tu), University Health Network, Toronto, Ont.

Contributors: All of the authors contributed to the conception and design of the work and interpretation of data. Data were accessed through the existing UTOPIAN database. Karen Tu has oversight over data acquisition for UTOPIAN and led the attainment of grant funding to conduct this study. Ellen Stephenson and Jessica Gronsbell performed the analysis of the data. Ellen Stephenson and Braden O'Neill drafted the manuscript. All of the authors revised the manuscript critically for important intellectual content, gave final approval of the version to be published and agreed to be accountable for all aspects of the work.

Funding: This study was funded by a Canadian Institutes of Health Research Operating Grant: COVID-19 Mental Health \& Substance Use - Matching Access to Service with Needs (450302). Braden O'Neill, Debra Butt, Noah Crampton and Karen Tu all received Research Scholar Awards from the Department of Family and Community Medicine at the University of Toronto.

Content licence: This is an Open Access article distributed in accordance with the terms of the Creative Commons Attribution (CC BY-NC-ND 4.0) licence, which permits use, distribution and reproduction in any medium, provided that the original publication is properly cited, the use is noncommercial (i.e., research or educational use), and no modifications or adaptations are made. See: https://creativecommons.org/licenses/by-nc-nd/4.0/

Data sharing: Analytic code used for this study is archived within the UTOPIAN Data Safe Haven and is available upon request.

Supplemental information: For reviewer comments and the original submission of this manuscript, please see www.cmajopen.ca/content/9/2/ E651/suppl/DC1. 